\title{
The Dewar Benzene Radical Cation and its Ring Opening Reaction
}

\author{
Thomas Bally* Stephan Matzinger, and Pawel Bednarek \\ Contribution from the Department of Chemistry, University of Fribourg, Switzerland
}

\author{
Supporting Information, Part $2^{*}$ (pdf file)
}

Ref 50: M. J. Frisch, G. W. Trucks, H. B. Schlegel, G. E. Scuseria, M. A. Robb, J. R. Cheeseman, J. A. Montgomery, Jr., T. Vreven, K. N. Kudin, J. C. Burant, J. M. Millam, S. S. Iyengar, J. Tomasi, V. Barone, B. Mennucci, M. Cossi, G. Scalmani, N. Rega, G. A. Petersson, H. Nakatsuji, M. Hada, M. Ehara, K. Toyota, R. Fukuda, J. Hasegawa, M. Ishida, T. Nakajima, Y. Honda, O. Kitao, H. Nakai, M. Klene, X. Li, J. E. Knox, H. P. Hratchian, J. B. Cross, C. Adamo, J. Jaramillo, R. Gomperts, R. E. Stratmann, O. Yazyev, A. J. Austin, R. Cammi, C. Pomelli, J. W. Ochterski, P. Y. Ayala, K. Morokuma, G. A. Voth, P. Salvador, J. J. Dannenberg, V. G. Zakrzewski, S. Dapprich, A. D. Daniels, M. C. Strain, O. Farkas, D. K. Malick, A. D. Rabuck, K. Raghavachari, J. B. Foresman, J. V. Ortiz, Q. Cui, A. G. Baboul, S. Clifford, J. Cioslowski, B. B. Stefanov, G. Liu, A. Liashenko, P. Piskorz, I. Komaromi, R. L. Martin, D. J. Fox, T. Keith, M. A. Al-Laham, C. Y. Peng, A. Nanayakkara, M. Challacombe, P. M. W. Gill, B. Johnson, W. Chen, M. W. Wong, C. Gonzalez, and J. A. Pople, Gaussian, Rev B.01 and C.01, Gaussian, Inc., Wallingford CT, 2004.

Ref 54: $\quad$ H.-J. Werner, P. J. Knowles, M. Schütz, R. Lindh, P. Celani, T. Korona, G. Rauhut, F. R. Manby, R. D. Amos, A. Bernhardsson, A. Berning, D. L. Cooper, M. J. O. Deegan, A. J. Dobbyn, F. Eckert, C. Hampel, G. Hetzer, A. W. Lloyd, S. J. McNicholas, W. Meyer, Molpro version 2002.6, Birmingham, UK., 2006, http://www.molpro.net

Figure S1: Ionization of dewar benzene (1) in Ar leads to some spectral features that are identical to those seen after ionization of benzene under the same conditions, in addition to the broad $600 \mathrm{~nm}$ band seen also in Freon

Figure S2: $\quad$ potential curves for folding the radical cation of dewar benzene, $\mathbf{1}^{\bullet+}$, at different levels of theory (using geometries optimized by B3LYP/6$31 \mathrm{G}^{*}$ for fixed values of $\omega$ ).

Figure S3: dependence of the transitions of the radical cation of dewar benzene $\mathbf{1}^{\bullet+}$, predicted by CAS(5,6)PT2/ANO-S on the dihedral angle $\omega$.

Figure S4: Photoelectron spectrum of dewar benzene 1 (from G.Bieri \& E. Heilbronner, Tetrahedron Lett. 8, 581 (1975)) and predictions from CAS$(5,6) \mathrm{PT} 2 / \mathrm{ANO}-\mathrm{S}$ calculations (at the B3LYP/6-31G* geometry of neutral dewar benzene). The ground-state energy is made to coincide with the maximum of the first PE band.

*) The first part of the Supporting Information (text file) contains the cartesian coordinates and and absolute energies of all stationary points located in this study. 


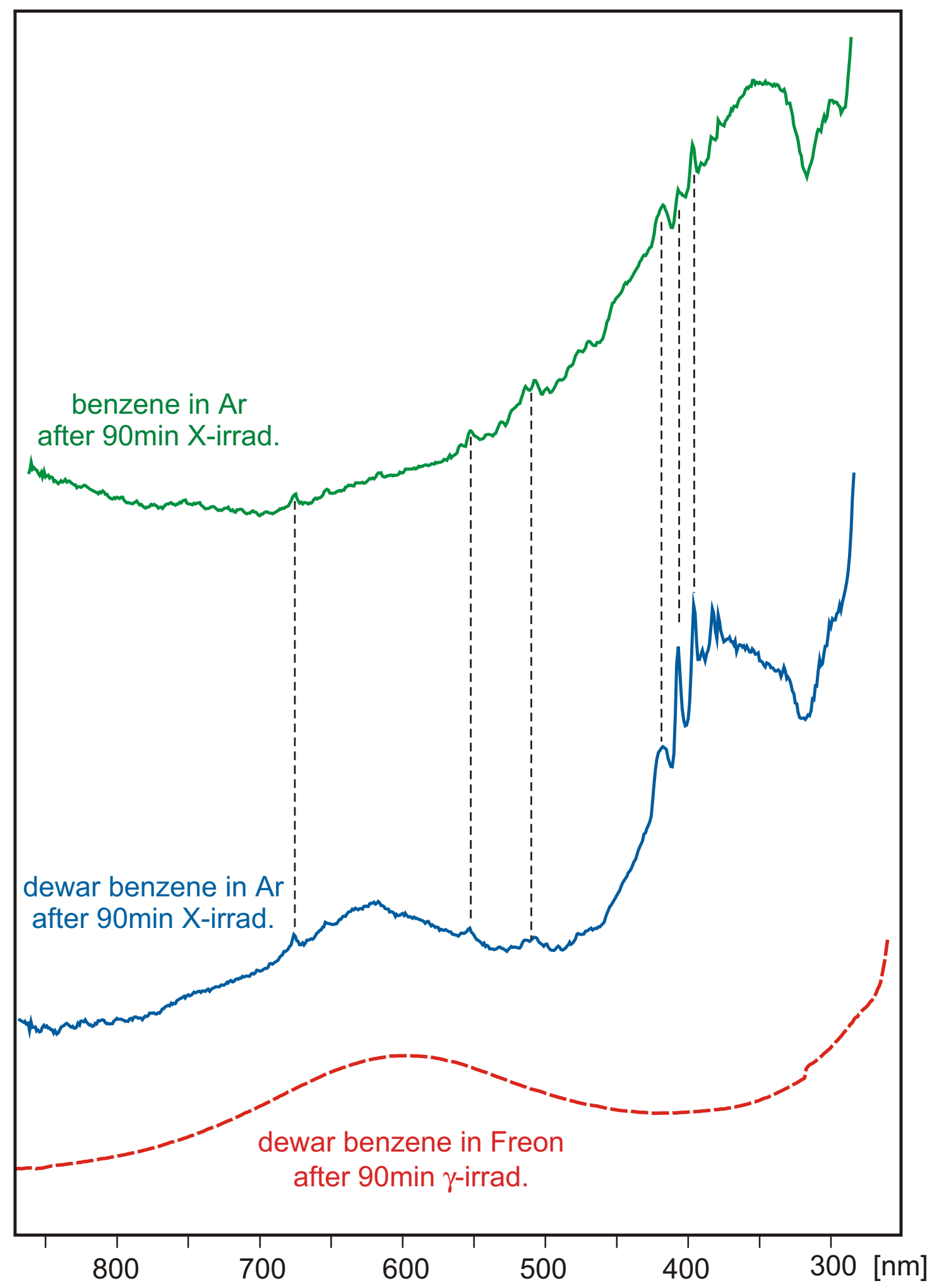

FigureS1: Ionization of dewar benzene (1) in Ar leads to some spectral features that are identical to those seen after ionization of benzene under the same conditions, in addition to the broad $600 \mathrm{~nm}$ band seen also in Freon. 


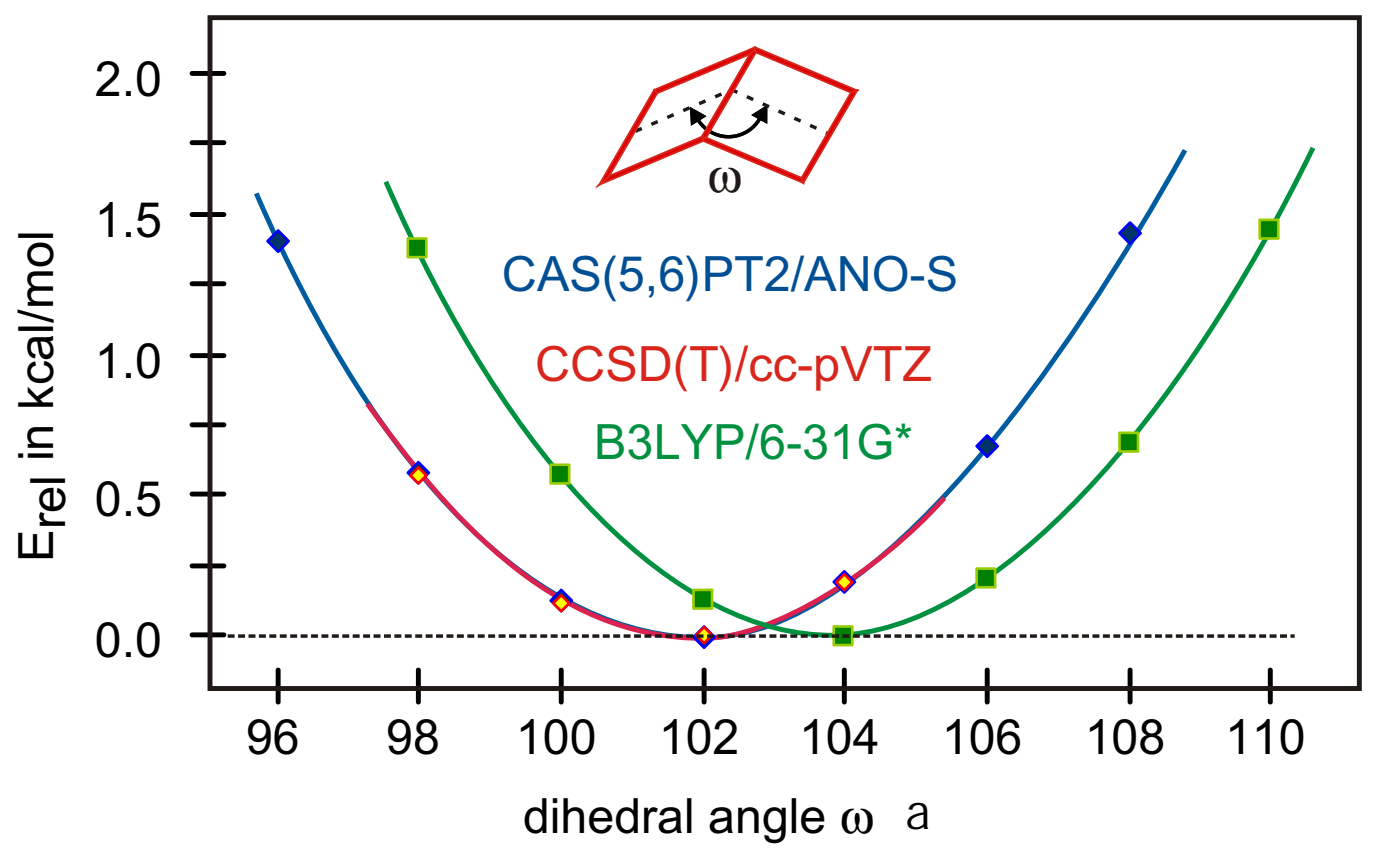

Figure S2: potential curves for folding the radical cation of dewar benzene at different levels of theory (using geometries optimized by B3LYP/6-31G* for fixed values of $\omega$ )

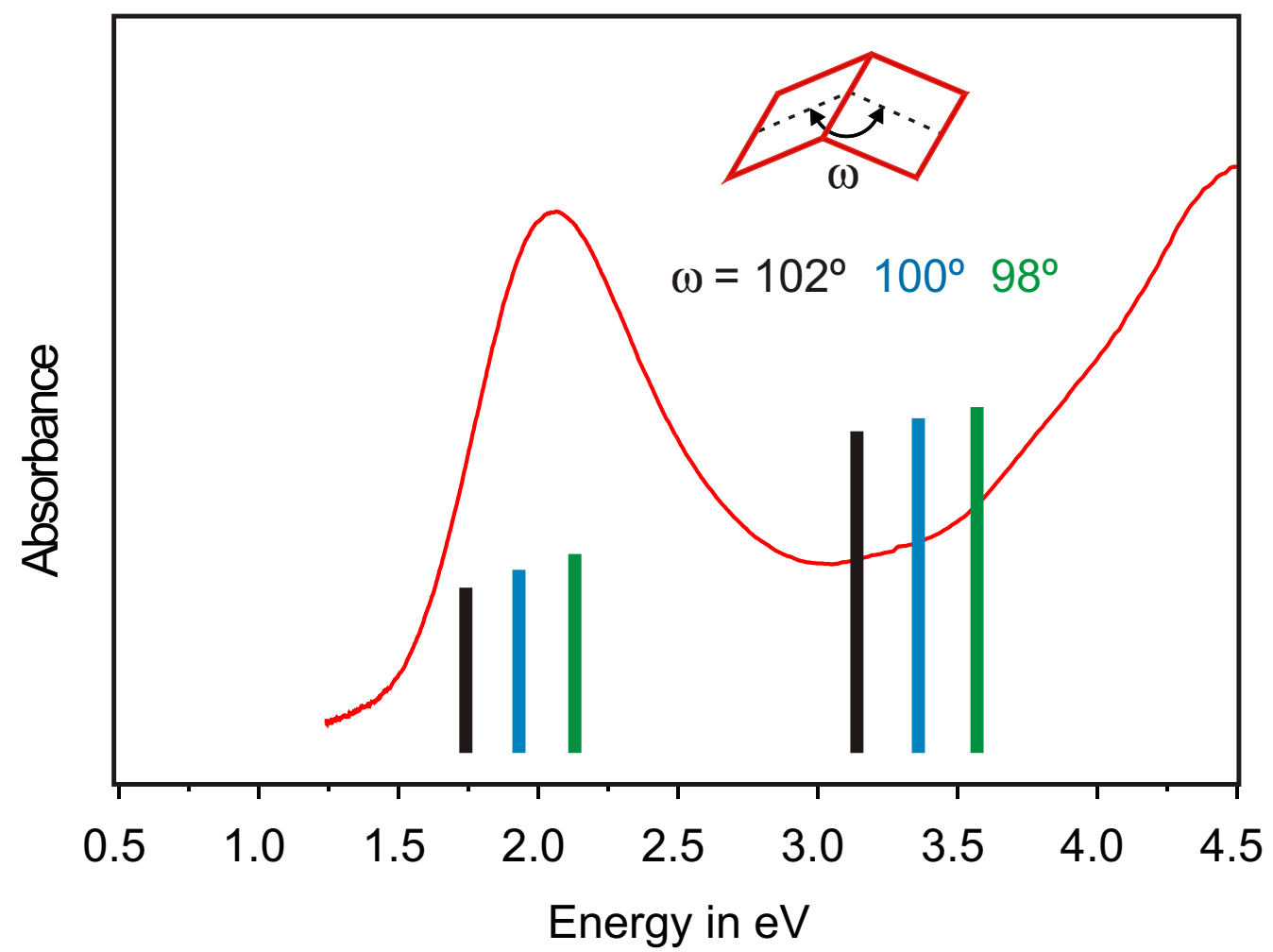

Figure S3: dependence of the transitions of the radical cation of dewar benzene predicted by CAS(5,6)PT2/ANO-S on the dihedral angle $\omega$. 


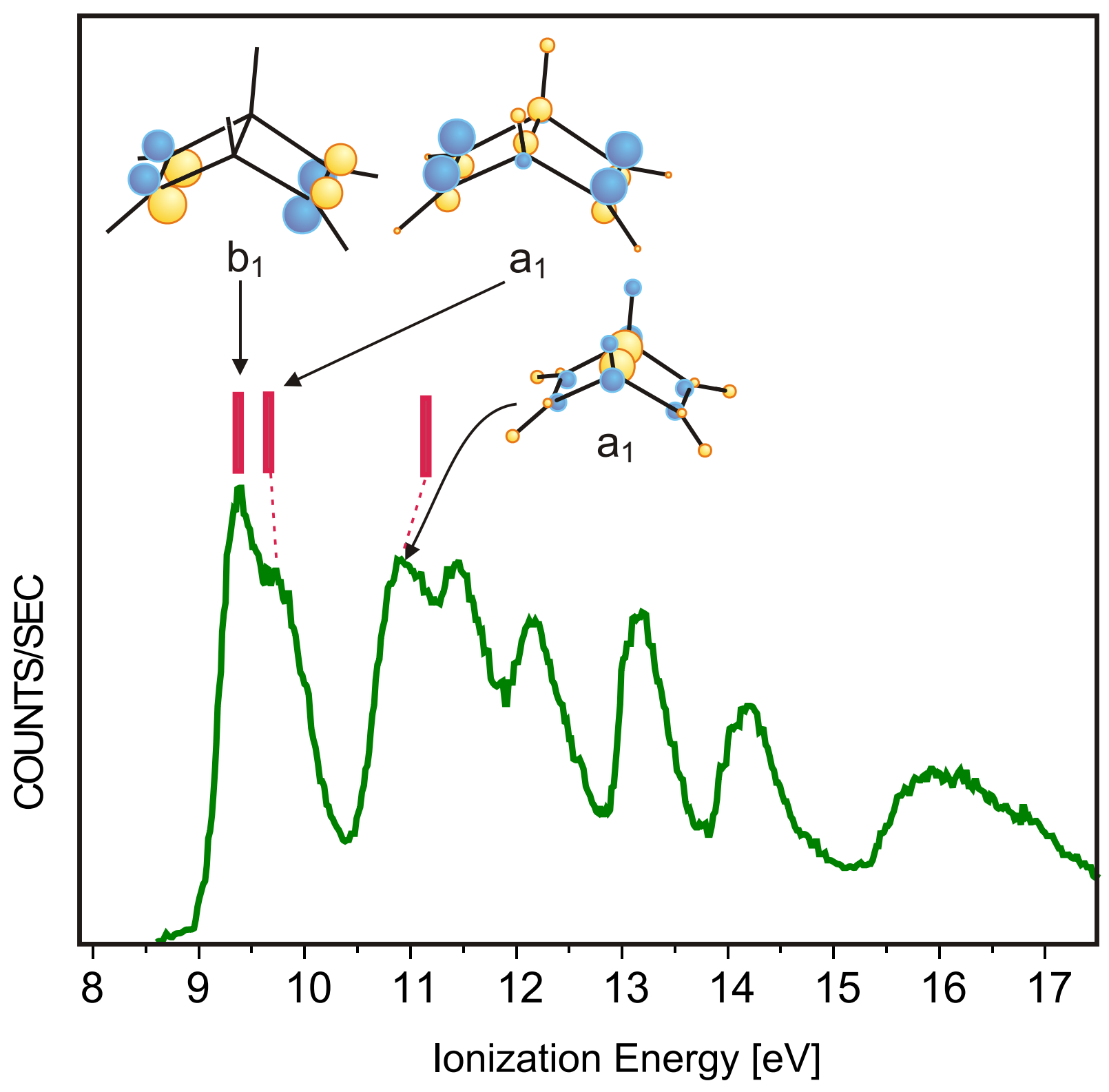

Figure S4: Photoelectron spectrum of dewar benzene (from G.Bieri \& E. Heilbronner, Tetrahedron Lett. 8, 581 (1975)) and predictions from CAS(5,6)PT2/ANO-S calculations (at the B3LYP/6-31G* geometry of neutral dewar benzene).

The ground-state energy is made to coincide with the maximum of the first band in the photoelectron spectrum. 